\title{
Value Co-Creation and Co-Destruction in Connected Tourist Experiences
}

\author{
Barbara Neuhofer \\ BU eTourismLab \\ Bournemouth University, United Kingdom \\ bneuhofer@bournemouth.ac.uk
}

\begin{abstract}
Information and communication technologies (ICTs) have become a key resource that has transformed travel and tourist experiences. Due to the increasing ubiquity and mobility of ICTs, they have become integral in creating connected experiences that interlink travel with everyday life. While recent studies have investigated value co-creation and the enhancement of experiences through ICTs, there is less knowledge about potential value co-destruction when ICTs come into place. This paper provides a first exploratory study to examine technology resource integration by looking at the dichotomous relationship of value co-creation and value co-destruction in connected tourist experiences. By adopting a qualitative in-depth methodology, this study has identified six dimensions, which highlight how value can be created and destroyed through connectedness. The paper contributes to service-dominant logic, resource integration and value creation discourses in a tourism and technology context, for which several theoretical and practical limitations are discussed.
\end{abstract}

Keywords: Value co-creation; value co-destruction; tourist experience; ICTs; connection;

\section{Introduction}

Value co-creation has become a recognised concept in services and tourism marketing research and practice. Hand in hand with the increasing empowerment of consumers and the proliferation of ICTs, the service-dominant (S-D) logic emerged (Vargo \& Lusch, 2004). It proclaimed co-creation as the next practice of experience and value creation (Prahalad \& Ramaswamy, 2004) and has gained wider attention in tourism in recent years (Binkhorst \& Den Dekker, 2009). ICTs have been portrayed as key tools to enable, facilitate and enhance tourist experiences and create added value in numerous ways (Tussyadiah \& Fesenmaier, 2009; Wang, Xiang, \& Fesenmaier, 2014a). In particular, social media and networking tools (Fotis, Buhalis, \& Rossides, 2011; Sigala, 2012a; Xiang \& Gretzel, 2010), mobile devices and smartphones (Wang, Xiang, \& Fesenmaier, 2014b) have encouraged individuals to connect and engage, and in turn co-create their experiences with a plethora of actors on an unprecedented scale (Ramaswamy, 2011). These connected and socially-dense practices have led to richer, more personal and meaningful experiences (Gretzel \& Jamal, 2009; Ramaswamy \& Gouillart, 2008), offering consumers a new level of experiences, which have been coined as 'technology enhanced tourist experiences' by recent research (Neuhofer, Buhalis, \& Ladkin, 2013).

In an attempt to accelerate the co-creation debate, several studies have conceptualised and explored experience and value co-creation in tourism in the digital context (Neuhofer, Buhalis, \& Ladkin, 2012; Schmidt-Rauch \& Schwabe, 2013; See-To \& 
Ho, 2014). While these and further studies have primarily investigated how technology can be used as a resource to enhance experiences and create added value, little emphasis has been placed on understanding how technology could potentially 'co-destruct' the value in the tourist experience. By drawing upon the recent S-D logic perspectives (Akaka \& Vargo, 2014), there is evidence that not all resources are value-adding but can be value-destroying, effectively leading to diminished experiences and value. The role of technology in the context of tourist experiences has not been scrutinised through the framework of value co-destruction to date. Based on this gap, this study adopts the S-D logic to explore technology resource integration in tourist experience through the dichotomous value co-creation and value codestruction perspective. Specifically, it aims to understand how the use of technology allows for value to be co-created or co-destroyed in connected tourist experiences. This study shall expand S-D logic discourses in the tourism and IT domain and offer a more critical perspective on how tourist experiences are shaped when ICTs come into place. The paper is divided into four main sections. It first contextualises the idea that we live in an era of connectedness, before providing the theoretical foundations of resource integration, value co-creation and value co-destruction. Second, the methodological design by means of a qualitative enquiry is explained and third the findings are presented, revealing six dimensions of value co-creation and codestruction. In the final section conclusions are drawn, proposing an agenda for further research and offering implications for tourism management and practice.

\section{Theoretical Background}

\subsection{An Era of Connectedness}

With the proliferation of ICTs, the potential for experiences and value to be cocreated has "exploded on an unprecedented scale everywhere in the value creation system" (Ramaswamy, 2009b, p.17). While tourism traditionally lagged behind in discussing co-creation in research and applying its principles in practice, it is evident that co-creation has gained increasing recognition. Particularly in the field of technology, scholarship has highlighted the potential of ICTs to mediate experiences and enable opportunities for co-creation in a number of different ways (Tussyadiah \& Fesenmaier, 2009; Wang, Park, \& Fesenmaier, 2012). Tourists use social media and networking applications as central tools to connect and share experiences (Kim \& Tussyadiah, 2013; Neuhofer et al., 2012), engage and co-create experiences with an array of actors, e.g. companies, at any time (McCabe, Sharples, \& Foster, 2012; Sfandla \& Björk, 2013; Sigala, 2012b). Mobile technologies are key tools to amplify these practices to gather information (Wang et al., 2012) and support experiences by involving these networks anywhere on the move (Kim \& Tussyadiah, 2013).

As a result of society's accelerated and inherently mobile lifestyle (Gretzel \& Jamal, 2009), technology has become a critical tool to connect, share and co-create with others, thereby interlinking travel and everyday life (Wang et al., 2014a). ICTs have transformed the nature of the tourist experience, allowing tourists to experience the physical travel environment, while staying connected in the online space and engage with physically distant environments at the same time (Neuhofer, Buhalis, \& Ladkin, 2014). This has led to an 'era of constant connectedness', in which tourist experiences are no longer isolated events, but are at the intersection of travel, work and life. 
Numerous benefits unfold as tourists use ICTs to connect, share and create distinct value as experiences become extended and intensified. However, there appears to be less understanding of how value might be co-destructed by integrating ICTs in order to facilitate such 'connected experiences'. Based on the assumption that travel fulfils the purpose of the reversal of everyday life, escapism and disconnection from the mundane (Cohen, 1979), it is thus of significance to evaluate whether there exist diminishing effects of ICTs resource integration on tourist experiences. By adopting the constructs of value co-creation and value co-destruction as theoretical vehicles, this paper now turns to examine the 'flipside' of technology to understand how value might be destroyed as ICTs become integrated and used. For this purpose, resource integration, value co-creation and co-destruction are contextualised in tourism next.

\subsection{Resource Integration}

At the core of the S-D logic is the notion of 'resource integration' (Vargo, Maglio, \& Archpru-Akaka, 2008), suggesting that individual actors integrate two types of resources, operand and operant resources, to allow for experiences and value to emerge (Vargo \& Lusch, 2004). In tourism, operand resources are usually tangible resources (e.g. materials, amenities and natural resources) that need action taken upon to create value, while operant resources are usually described as intangible resources (e.g. human skills and knowledge) that can be integrated to act upon another resource (Akaka \& Vargo, 2014). While the resource debate has been extensive, the role of technology has only been scarcely explored to date (Akaka \& Vargo, 2014). The premise of the S-D logic postulates that resources per se do not carry any value, but value is only co-created by the tourist when specific resources (e.g. technology) are put into use. This means that value does not automatically exist within a given device or application, but unfolds when an individual integrates it in a specific need situation (e.g. real-time transport app, restaurant review). Assuming that the integration of ICTs is contextually shaped by the tourist's use behaviour, ICTs might induce a co-creation (enhancement) or co-destruction (diminishment) of experiences and value.

\subsection{Value Co-Creation}

Co-creation has introduced a new practice for services marketing, innovation and experience creation (Vargo \& Lusch, 2004; Vargo et al., 2008) that has re-shaped our understanding of how contemporary interactions, experiences and value are created and constructed (Ramaswamy, 2009a). This perspective has provided a new fundament for tourism studies to explain that tourists have become empowered actors, who a) engage with other actors (e.g. tourism businesses, consumer communities, personal networks and wider stakeholders), b) integrate their resources (e.g. information, platforms and devices) and c) participate in the design and creation of their experiences (Ramaswamy, 2009a). Tourists plan their travel online, personalise their hotel stay, connect with locals to get destination insights and contribute to review platforms online. Co-creation postulates that companies merely facilitate 'experience environments' for tourists (the beneficiaries), who use their resources for unique value to be extracted. One factor that has particularly maximised value cocreation is technology. Technology is a game changer that has fostered co-creation everywhere along the value creation system (Neuhofer et al., 2012). 


\subsection{Value Co-Destruction}

Expanding on the foundational premise that resource integration and value creation are contextually driven, it can be argued that value creation might not always be positive, but could also be negative in instances. This argument has been increasingly promoted in recent S-D logic discourses, drawing attention to the novel concept of 'value co-destruction' (Chathoth, Altinay, Harrington, Okumus, \& Chan, 2013; Plé \& Chumpitaz Cáceres, 2010). While the majority of scholarship has focused on positive value co-creation, value co-destruction has been largely treated as an implicit construct (Lefebvre \& Plé, 2011). Value co-destruction acknowledges that value might not be created but destroyed by the actors (e.g. the tourist) or the resources (e.g. technology) that are integrated in the process. As such, co-destruction might occur on a voluntary (intentional) or involuntary (accidental) level, with resources leading to an overall diminishment of value (Plé \& Chumpitaz Cáceres, 2010). Considering resource integration as phenomenological (Helkkula, Kelleher, \& Pihlström, 2012), it is important to adopt a more critical perspective to understand ICTs as a resource. Although technology might be "a resource at one level, the same technology could be considered as a resistance at a different level, or different context" (Akaka \& Vargo, 2014, p.374).

With this premise in mind, this study enters new theoretical territory by empirically exploring ICTs resource integration in tourist experiences through a S-D logic-driven co-creation and co-destruction lens. Studies exploring potential drawbacks and challenges of ICTs use in the context of tourist experiences are scarce to date. Only Pearce and Gretzel (2012) studied positive and negative experiential outcomes in socalled 'technology dead zones'. Paris, Berger, Rubin, and Casson (2015) examined technology induced tensions in disconnected and unplugged tourist experience and Neuhofer, Buhalis, and Ladkin (2015) investigated technological enablers and barriers of tourist experience creation. Building upon this emerging stream of research, tackling ideas surrounding disconnection, barriers and issues of technology, this study shall contribute to a resource-based view and generate answers as to how technology 'adds value' or 'diminishes value' in connected tourist experiences.

\section{Methodology}

A qualitative enquiry was employed in order to extract the subjective experience narratives from individuals to understand co-creation and co-destruction practices in experiences through ICTs. Qualitative in-depth interviews were conducted, guided by a semi-structured interview instrument and an iterative interview process that allowed adapting the instrument on a continuous basis. The findings presented in this paper, which are part of a larger study, were mainly driven by two research questions. These are: a) how does the integration of ICTs enhance the tourist experience? and b) how does the integration of ICTs diminish the tourist experience? By asking participants an array of questions pertaining to positive and negative effects of technology use, a balanced view could be gathered shedding light on value co-creation and codestruction. The sampling procedure followed a purposive technique, due to the reason that participants needed to fulfil a specific set of prerequisites to participate in the study (Bryman, 2008). 
Participants had to meet the following three criteria to be: a) technology-savvy consumers (defined as owners of smartphones and daily users of smartphones and social media), b) prior experience of using ICTs for travel activities and c) the use of ICTs for travel within the last 12 months to ensure the recollection of their experiences. Due to the need for in-depth narratives, a total of 15 interviews were conducted over a two-month period, with consumers having been identified in the geographical proximity of the researcher in the UK. Beyond the sample criteria, the profile of the participants can be considered similar to those of 'early adopters of technology' (Rogers, 2003), in terms of early technology adoption and general use behaviour. To extract the narratives, interviews lasted between one hour and two hours and a half each, leading to an average length of one hour and 24 minutes.

All interviews were voice-recorded and manually transcribed verbatim by the researcher in order to allow for a rigorous coding and analysis process (Rubin \& Rubin, 2004). A qualitative thematic analysis was performed, following the principles suggested by Miles and Huberman (1994). To ensure a rigid analysis, a detailed sixstage coding process was developed, consisting of inductive broad brush coding of initial codes, coding-on, distilling, sorting and meta-coding, refining codes and clustering, and developing final themes and dimensions of the study. For this process, the computer software QSR NVivo 10 was used to store, organise and manage the wealth of data, including 286 pages of written transcripts. While criteria, such as reliability and generalisability generally play a minor role in qualitative research (Creswell, 2003), this study applied researcher reflexivity, contextualisation, prolonged data engagement, thick description and triangulation. Table 1 presents the socio-demographic profile, which reflects a range of demographic factors, including a balance of gender, age, education levels and nationalities. This research does not make claims of generalisability to the population, but can be considered as transferable to broadly mirror the profile of early adopters in the wider population.

Table 1. Socio-demographic sample profile

\begin{tabular}{lllllll} 
Nr. & Pseudonym & Gender & Nationality & Education & Age & Smartphone \\
\hline 1 & Laura & Female & Dutch & A-Levels & $20-29$ & Samsung \\
2 & Jane & Female & German & Postgraduate & $20-29$ & iPhone \\
3 & Martha & Female & German & Undergraduate & $20-29$ & iPod/iPhone \\
4 & Veronica & Female & Chinese & Postgraduate & $40-49$ & iPhone \\
5 & Sam & Male & British & A-Levels & $20-29$ & Samsung \\
6 & Paul & Male & British & Postgraduate & $60-69$ & iPhone \\
7 & John & Male & Indonesian & Postgraduate & $30-39$ & Blackberry \\
8 & Sandra & Female & Greek & Postgraduate & $20-39$ & HTC \\
9 & Teresa & Female & Indonesian & Undergraduate & $20-39$ & HTC \\
10 & Andrew & Male & Pakistan & Postgraduate & $30-39$ & Samsung \\
11 & Dan & Male & Greek & Postgraduate & $40-49$ & Blackberry \\
12 & Aaron & Male & Italian & Postgraduate & $30-39$ & iPhone \\
13 & Steve & Male & Belarus & Postgraduate & $30-39$ & Samsung \\
14 & Rachel & Female & German & Postgraduate & $20-29$ & Blackberry \\
15 & Hanna & Female & Vietnamese & Postgraduate & $30-39$ & iPhone \\
\hline
\end{tabular}




\section{Results and Discussion}

The findings of the qualitative study shed light on ICTs as an important resource of value co-creation and value co-destruction in connected tourist experiences. Through the detailed coding process a total of six dimensions, which are presented and discussed below.

\subsection{Value co-creation: Connection as a means of value creation}

The first set of findings relate to the theme of 'value co-creation' and indicate how tourists integrate ICTs and positive value is co-created and extracted through connected tourist experiences. The identified themes include 1) social connectedness, 2) social sharing and co-living, 3) mental detachment and de-territorialisation.

\section{1) Social Connectedness}

As first and dominant theme emerged, participants reported a sense of 'social connectedness' that is created through the integration and use of ICTs. Connectedness has been highlighted as a crucial part of participants' tourist experiences to compensate the feeling of being physically distant from home. The narratives indicate that tourists connect through a variety of mobile devices, such as smartphones and tablets, to a) maintain a link to their everyday lives and b) be able to keep up their mundane routines. The narratives pointed to an interesting connection paradox. One the one hand, tourists want to fully immerse themselves into the experience at the destination, while at the same time, they seek to use ICTs to create connectedness with people and activities relating to home. Through this practice tourists extract added value as it permits them to remain in contact with their social network, not only for updates, but importantly to avoid feeling spatially and temporarily isolated from their 'usual lives'. The most noteworthy value creation occurs as ICTs are integrated to create an interconnection between the three dimensions of the 'tourist life', 'private life' and 'work life'. Many participants reported to use ICTs as a key resource to stay in touch with family, friends and also the work community, and enhance their experiences through this process. Overall, ICTs are perceived as a crucial resource to maintain personal bonds and the sense of closeness with friends and family, but also create a feeling of security of having 'virtual companions' in a connected experience.

"In the past if you don't have the smart phone, you are stuck when you were travelling (...) Like this, when I travel in another country, I work and update like normal, and people don't feel like 'oh she is on holiday or she is on leave I have to wait another week to get the answer'." (Hanna)

"I think the whole experience gets more interactive and you include like your private life and your restaurant experience and in some cases even your work, it's all happening together." (Martha)

"If you don't and can't interact with the people around you, because you might not know them, then it is nice to have a conversation or have this kind of sense that other people are still around you, even though it is kind of virtual, it gives you kind of a security, and then you are more willing to share the experience." (Rachel) 


\section{2) Social sharing and co-living}

'Social sharing and co-living' through ICTs emerged as the second theme leading to positive value co-creation for the tourist. Sharing of experiential impressions and moments through ICTs, in particular social media, has become an integral practice of the tourist experience (Munar \& Jacobsen, 2014). The findings reveal that tourists have a desire to share their trips live, in the moment, with others. Depending on the intensity of the sharing practice, value is co-created as tourists get connected, share experiences with others and allow the network to go as far as 'co-live' travel by being connected online. The majority of participants vividly recalled instances in which sharing with the connected social network has occurred as part of enhancing the tourist experience on-site. By inspiring, influencing and recommending places worth visiting, participants noted to feel like having accomplished something positive for others. Tourists want to bring unique things to people's attention, show them meaningful insights and be informative for others trying to find nice places in the future. In increasing the intensity of being connected, the narratives indicated that technology is used as a resource to invite the network to become part of the experience itself. Beyond a simple sharing mechanism, this practice allows other actors in the social network to become virtual co-participants of the tourist's lived experience, resulting in a co-created value sensation of 'being there with you'.

"It makes me feel good, because I know that if they feel the same way about these kind of places, they will have a really nice experience themselves." (Rachel)

"Just the feeling to have the other people participating in your journey even though they are not there but to share your experience with". (Jane)

\section{3) Mental detachment and de-territorialisation}

In sharp contrast to the notion of living the tourist experience as a way to dissociate from everyday life (Cohen, 1979), the findings revealed a third dimension of value co-creation in connected experiences, which can be described as 'mental detachment' or 'de-territorialisation'. As tourists use their devices to connect to their networks, it was found that they often do so to 'switch to distant places'. Participants mentioned to seek social interactions online that allow them to move to a 'virtual territory', while temporarily and mentally disconnecting from their physical surroundings. A distinct number of participants highlighted the need and desire to 'take a break from the tourist experience' in the physical space and interact with distant actors (e.g. friends and family) online. Temporarily detaching from the surroundings and shifting to the online world has been described as a unique practice facilitated by the integration of ICTs. This momentary 'absence' that is sought after particularly creates a mechanism to fill time during experiential downtimes and boredom and serves as a means of change to interact with people other than the physically present travel companions. Teresa exemplifies a past tourist experience, capturing such representative behaviour:

"I think that happens plenty of times and you sit down in a café and you enjoy your meal and you have to wait for certain minutes until the food arrives, and when there is nothing on the table and we are exhausted to talk to one another then we just engage with our virtual friends." (Teresa) 
"Sometimes when we are really exhausted, they all have an Internet connection we just silence for a few minutes and everyone keeps updating their Facebook or Twitter and then we realise that we are still silent because we keep busy with our activities on the viral world." (Teresa)

\subsection{Value co-destruction: Connection as a means of value destruction}

The second part of the findings relates to 'value co-destruction' and reveals how value is diminished and destroyed when ICTs come into play. The analysis revealed three main themes, including 1) barrier to escapism from everyday life and relaxation, 2) interference of 'living' the experience and 3 ) pressure and addiction.

\section{1) Barrier to Escapism from Everyday Life and Relaxation}

The first theme highlighted that technology can diminish the value of the tourist experience as it provides an almost 'inevitable' connection and in turn creates a barrier that prevents tourists from escaping from their everyday lives. While the use of ICTs for connection might create distinct benefits and added value in some contextual situations, the majority of participants reported it is a potentially valuedestructing feature. Participants highlighted that the integration of ICTs to use applications and connect to networks online can significantly decrease the sense of escapism and possibility of true relaxation. By remaining connected with the home environment, participants noted that they seem to lose the sense and purpose of travelling, being able to immerse in the destination and living the 'tourist life'. In a similar vein, other participants highlighted that the extensive ICTs use renders it difficult to refresh, renew and recreate while being away.

\footnotetext{
"I would say that social networks are more distraction because it keeps you away from actually being in the location and not enjoying the place and time you are spending there (...) Because when you are entering a social network you are always somewhere else in a virtual world and then you are not really in the destination anymore, I mean not with your thoughts." (Jane)
}

"Because if I connect so much it is not kind of travelling anymore, you are, I don't know, I just really like I want to get off the daily life, so I seek the reality, because if you stick so much with technology you don't really enjoy the place you live, technology should just support you to enjoy, it doesn't mean that it should prevent you from enjoying." (Hanna)

\section{2) Interference of 'Living' the Tourist Experience}

In close line with the first dimension, a second distinct theme emerged, suggesting that value co-destruction occurs as ICTs can create an 'interference' of living and enjoying the 'real' tourist experience on-site. The majority of participants highlighted this theme when asked whether ICTs could diminish the experience in any way. The findings reveal that the use of ICTs can destroy value, as the engagement with technology dominates the activities that are associated with travel. For instance, participants recalled several past travel events, when they were focussed on 'taking pictures for later' rather than enjoying the experience in the 'now', or when they engaged in excessive posting and sharing practices, rather than seeing and living things happening in the immediate surroundings. In many cases, this has led to a reported diminishment of living the own experience, as priority has been given to showing and living the experience for 'the others'. The following quotes exemplify 
the perceived value co-destruction when tourists themselves use ICTs in a way that they keep them from enjoying their experiences.

"If you bring the camera to the holiday and all the time you look everything through the camera, you photo everything, what is the point?" (Hanna)

"Well I think when you don't watch out that you lose the purpose of your actually relaxing experience or this leisure kind of thing. Because in the past it was like that when you left the house you weren't connected, you were in another place and your mind could go somewhere else and could relax for the rest of the day. But NOW that you are connected I think you have to find a good balance that you don't get too busy with these things." (Martha)

"Somebody that would take an image, post it on Facebook or Instagram and then would have the map and the phone out all the time, and the iPad, and kind of, I think that I feel that somebody who uses technology that much to that extent, cannot actually enjoy that places that much, because you are so caught up in sharing it with other people rather than enjoying it yourself that much." (Rachel)

"It was like we were shooting pictures in order to take home a bit of the destination and maybe, not experiencing the real destination once we were there. It is like we stored all this information, because then when I have time I can experience that. While tourism is about experiencing it NOW." (Aaron)

\section{3) Sense of pressure and addiction}

The third theme highlights ICTs as a value destroying resource in connected experiences, primarily by creating a perceived sense of 'pressure and addiction' during travel. The majority of participants reported that the mere availability of ICTs (e.g. Internet connection, devices, social media) does create a self-induced pressure to use technology during travel. While participants noted connectedness and sharing through ICTs as a positive form of value creation, many narratives indicated that tourists perceive their own behaviours as both distractive and destructive to their experiences. In fact, participants confirmed that they frequently feel socially pressured and obliged to take pictures of their experiences, upload and post these. These sharing practices have however been reported as time-absorbing and forced, with one participant, saying that one becomes 'a slave of technology'. The findings indicate that dominant technology integration can render ICTs far from being a valuegenerating resource. Quite the opposite, it was noted that the self-inflicted pressure of having to connect and share can potentially reduce value. The following quotes exemplify such value co-destruction.

"I've a lot of friends, technology addicted, and they say that they are experiencing a destination, but ACTUALLY they are not. They are in their iPhones, they are not looking at the beauty of the landscape or the nice restaurant, or the company they have at the restaurant, so I think technology is extremely relevant but we are still in the REAL world" (Aaron)

"It sets me under pressure. Yeah (affirmative). Yes because you always feel that you are on stand-by to be connected to all the social network." (Jane)

"A lot of people upload everything they see they upload on Facebook, but I don't like that idea, this is becoming a slave, like everything - this is not necessary." (Hanna) 


\section{Conclusion and Recommendations}

The emergence and proliferation of an increasing amount of ubiquitously integrated social and mobile technologies have led tourists to connect and co-create their travel experiences and value on an unprecedented scale. In adopting the S-D logic perspective, this study aimed to explore technology as a resource of value co-creation and co-destruction in connected tourist experiences. While the existing literature has provided evidence that technology facilitates the co-creation and enhancement of tourist experiences (Akaka \& Vargo, 2014; Chathoth et al., 2013; Neuhofer et al., 2014), this paper has drawn attention to the flipside of technology. Six main dimensions were identified, ranging from the benefits of sharing, co-living and detachment to the value-diminishing potential of ICTs to create barriers to escapism, experience interference and pressure in experiential settings. This leads to conclude that ICTs are resources that do not possess value and cannot be defined 'as good or bad' technology for travel per se. Rather, it is through technology use and application that value is contextually created or destroyed by tourists as individual actors. These findings lead to critical theoretical and practical implications.

On a theoretical level, this study contributes to recent S-D logic discourses in services and tourism research, starting to conceptualise digital technology as an enabler for experience and value creation practices (Akaka \& Vargo, 2014). While technology will continue to play a significant role in many contemporary travel and leisure experiences, this study has highlighted that technology can potentially destroy experiences in contextual tourist use behaviour and application. The above presented insights contribute in that they have a) provided a starting point for a more differentiated understanding of the role of technology in resource integration and $b$ ) extended co-destruction discourses in the tourism domain. This study also calls for a sensitisation of technology resource-based discourses.

This is particularly critical for tourism practice. Technology does not automatically create value or is an all-experience-enhancing tool that generates value for all kinds of travel types, situations and experiences. Instead, technology needs to be considered as an operant resource (Akaka \& Vargo, 2014) that needs to be contextually meaningful to provide consumers with tools to integrate and co-create their own value in context and use. On the one hand, ICTs have the potential to facilitate more socially dense, connected and life-integrated experiences, which can to lead to so-called technologyenhanced tourist experiences and value extraction (Neuhofer et al., 2012). On the other hand, tourism organisations need to be aware that technology facilitation and technology-enabled experience environments can potentially become valuedestructing when tourists seek to escape, relax and break free from technology and desire to live in the moment and want to fully immerse in the tourist experience onsite. While the findings indicate that technology use behaviour and consequential value diminishment is often self-inflicted by tourists, tourism, destinations and hospitality organisations could potentially explore the facilitation of 'technologyfree', 'disconnected spaces' or 'digital detox' zones, which could limit value destruction and could provide tourists with a space to disconnect, lift perceived pressures and live the tourist experience without physical or social interferences. As a novel idea gaining accelerated attention, disconnection might be a worthwhile avenue to explore, as organisations could offer tourists distinct value propositions and 
resources (beyond technology) to co-create connected and disconnected experiences in the travel context. In this vein, further research is needed to strengthen our current understanding of value co-destruction in connected tourist experiences, and to go one step further to explore value co-creation in 'disconnected tourist experiences' in an era of constant connectedness.

\section{References}

Akaka, M.A., \& Vargo, S.L. (2014). Technology as an operant resource in service (eco)systems. Information Systems and e-Business Management 12(3): 367-384.

Binkhorst, E., \& Den Dekker, T. (2009). Agenda for co-creation tourism experience research. Journal of Hospitality Marketing \& Management 18(2/3): 311-327.

Bryman, A. (2008). Social research methods (3rd ed.). New York: Oxford University Press.

Chathoth, P., Altinay, L., Harrington, R.J., Okumus, F., \& Chan, E.S.W. (2013). Co-production versus co-creation: A process based continuum in the hotel service context. International Journal of Hospitality Management 32(1): 11-20.

Cohen, E. (1979). A phenomenology of tourist experiences. Sociology 13(2): 179-201.

Creswell, J.W. (2003). Research design: Quantitative, qualitative, and mixed methods approaches. Thousand Oaks: SAGE Publications.

Fotis, J., Buhalis, D., \& Rossides, N. (2011). Social media impact on holiday travel planning: The Case of the Russian and the FSU Markets. International Journal of Online Marketing 1(4): 1-19.

Gretzel, U., \& Jamal, T. (2009). Conceptualizing the creative tourist class: Technology, mobility, and tourism experiences. Tourism Analysis 14(4): 471-481.

Helkkula, A., Kelleher, C., \& Pihlström, M. (2012). Characterizing value as an experience. Journal of Service Research 15(1): 59-75.

Kim, J., \& Tussyadiah, I.P. (2013). Social networking and social support in tourism experience: The moderating role of online self-presentation strategies. Journal of Travel \& Tourism Marketing 30(1): 78-92.

Lefebvre, I., \& Plé, L. (2011). Emergence of value co-destruction in B2B context. In Gummesson, E., Mele, C. \& Polese, F. (Eds.), Service dominant logic, network \& systems theory and service science: Integrating three perspectives for a new service agenda. Napoli: Giannini.

McCabe, S., Sharples, M., \& Foster, C. (2012). Stakeholder engagement in the design of scenarios of technology-enhanced tourism services. Tourism Management Perspectives 4(October 2012): 36-44.

Miles, M.B., \& Huberman, A.M. (1994). Qualitative data analysis: An expanded sourcebook (2nd ed.). London: SAGE Publications.

Munar, A.M., \& Jacobsen, J.K.S. (2014). Motivations for sharing tourism experiences through social media. Tourism Management 43: 46-54.

Neuhofer, B., Buhalis, D., \& Ladkin, A. (2012). Conceptualising technology enhanced destination experiences. Journal of Destination Marketing \& Management 1(1-2): 36-46.

Neuhofer, B., Buhalis, D., \& Ladkin, A. (2013). A typology of technology-enhanced tourism experiences. International Journal of Tourism Research, 10.1002/jtr.1958: n/a-n/a.

Neuhofer, B., Buhalis, D., \& Ladkin, A. (2014). Co-creation through technology: Dimensions of social connectedness. In Xiang, Z. \& Tussyadiah, I. (Eds.), Information and communication technologies in tourism 2014 (pp. 339-352). Vienna, Austria: Springer.

Neuhofer, B., Buhalis, D., \& Ladkin, A. (2015). Technology as a catalyst of change: Enablers and barriers of the tourist experience and their consequences. In Tussyadiah, I. \& 
Inversini, A. (Eds.), Information and communication technologies in tourism 2015 (pp. 789-802). Vienna, Austria: Springer.

Paris, C.M., Berger, E.A., Rubin, S., \& Casson, M. (2015). Disconnected and unplugged: Experiences of technology induced anxieties and tensions while traveling. In Tussyadiah, I. \& Inversini, A. (Eds.), Information and communication technologies in tourism 2015 (pp. 803-816). Vienna, Austria: Springer.

Pearce, P.L., \& Gretzel, U. (2012). Tourism in technology dead zones: Documenting experiential dimensions. International Journal of Tourism Sciences 12(2): 1-20.

Plé, L., \& Chumpitaz Cáceres, R. (2010). Not always co-creation: Introducing interactional codestruction of value in service-dominant logic. Journal of Services Marketing 24(6): 430-437.

Prahalad, C.K., \& Ramaswamy, V. (2004). Co-creation experiences: The next practice in value creation. Journal of Interactive Marketing 18(3): 5-14.

Ramaswamy, V. (2009a). Co-creation of value: Towards an expanded paradigm of value creation. Marketing Review St. Gallen 26(6): 11-17.

Ramaswamy, V. (2009b). Leading the transformation to co-creation of value. Strategy \& Leadership 37(2): 32-37.

Ramaswamy, V. (2011). It's about human experiences......and beyond, to co-creation. Industrial Marketing Management 40(2): 195-196.

Ramaswamy, V., \& Gouillart, F. (2008). Co-creating strategy with experience co-creation. Balanced Scorecard Report 10(4): 1-3.

Rogers, E.M. (2003). Diffusion of innovations. 5th ed. New York: The Free Press.

Rubin, H.J., \& Rubin, I.S. (2004). Qualitative interviewing the art of hearing data. London: SAGE Publications.

Schmidt-Rauch, S., \& Schwabe, G. (2013). Designing for mobile value co-creation: The case of travel counselling. Electronic Markets 24(1): 5-17.

See-To, E.W.K., \& Ho, K.K.W. (2014). Value co-creation and purchase intention in social network sites: The role of electronic word-of-mouth and trust - A theoretical analysis. Computers in Human Behavior 31: 182-189.

Sfandla, C., \& Björk, P. (2013). Tourism experience network: Co-creation of experiences in interactive processes. International Journal of Tourism Research 15(5): 495-506.

Sigala, M. (2012a). Social networks and customer involvement in new service development (NSD): The case of www.mystarbucksidea.com. International Journal of Contemporary Hospitality Management 24(7): 966-990.

Sigala, M. (2012b). Web 2.0 and customer involvement in new service development: A framework, cases and implications in tourism. In Sigala, M., Christou, E. \& Gretzel, U. (Eds.), Social media in travel, tourism and hospitality: Theory, practice and cases (pp. 25-38). Farnham: Ashgate Publishing.

Tussyadiah, I.P., \& Fesenmaier, D.R. (2009). Mediating the tourist experiences: Access to places via shared videos. Annals of Tourism Research 36(1): 24-40.

Vargo, S.L., \& Lusch, R.F. (2004). Evolving to a new dominant logic for marketing. Journal of Marketing 68(January): 1-17.

Vargo, S.L., Maglio, P.P., \& Archpru-Akaka, M. (2008). On value and value co-creation: A service systems and service logic perspective. European Management Journal 26: 145- 152.

Wang, D., Park, S., \& Fesenmaier, D.R. (2012). The role of smartphones in mediating the touristic experience. Journal of Travel Research 51(4): 371-387.

Wang, D., Xiang, Z., \& Fesenmaier, D.R. (2014a). Adapting to the mobile world: A model of smartphone use. Annals of Tourism Research 48(0): 11-26.

Wang, D., Xiang, Z., \& Fesenmaier, D.R. (2014b). Smartphone use in everyday life and travel. Journal of Travel Research, 10.1177/0047287514535847.

Xiang, Z., \& Gretzel, U. (2010). Role of social media in online travel information search. Tourism Management 31(2): 179-188. 